\title{
Vibration suppression effects on rotating wind turbine blade using a particle damping method
}

\author{
Santosh R. Sandanshiv ${ }^{1}$, Umesh S. Chavan ${ }^{2}$ \\ ${ }^{1}$ Genba Sopanrao Moze College of Engineering, Pune, India \\ ${ }^{1,2}$ Vishwakarma Institute of Technology, Pune, India \\ ${ }^{1}$ Corresponding author \\ E-mail: ${ }^{1}$ santoshsandanshiv@yahoo.com, ${ }^{2}$ umesh.chavan@vit.edu \\ Received 7 August 2019; accepted 22 August 2019 \\ DOI https://doi.org/10.21595/vp.2019.20944
}

Check for updates

Copyright $(C) 2019$ Santosh R. Sandanshiv, et al. This is an open access article distributed under the Creative Commons Attribution License, which permits unrestricted use, distribution, and reproduction in any medium, provided the original work is properly cited.

\begin{abstract}
Due to the vibration of the wind turbine blade, the rate of electricity generation gets reduced. In this research, the focus is on reduction of wind turbine blade vibration. The important point is that in the attempt of vibration suppression, a new method of damping named particle damping has been tried. The novelty of this study is that this method is adopted for the first time in wind turbine blade for rotating condition. In this method, containers filled with spherical particles are mounted at four different positions on each blade alternatively. Taking tests at different rpm and container positions gives a different vibration suppression effect as compared to without damping and finding optimum positions for mounting of damper.
\end{abstract}

Keywords: wind turbine blade, vibration suppression, damper.

\section{Introduction}

Control of vibration in blade is necessary as it adversely affects electricity generation. According to Thomsen [1], the main modes of vibration in the blade are edgewise and flap wise. According to Dapeng [2], edgewise vibration is the main problem in most of the blades. Giguere [3] gives a characteristic which provides important findings of dynamic characteristics. Mainly load acting on the blade is wind load and many scientists have already worked by blade element momentum method (BEM) for calculating aerodynamic load of a blade. Extreme wind turbine load investigation, using different methods, are studied by Saranyasoontorn [5]. Typhoon winds are critically analyzed for the investigation of turbulent conditions, Ishizaki [4]. The damage of structural parts like nacelle cover and blades of wind turbine are investigated by Maalami [6] and Duquette [7]. Passive damper is inserted in wind turbine tower for minimizing vibration induced by wind loads, Murtagh [8]. Krenk [11] introduces active struts mounted near the root of each blade for reducing blade vibrations. For mitigating edgewise vibrations active tuned mass damper is investigated by Fitzgerald [10]. A roller damper and a tuned liquid column damper (TLCD) inside a rotating blade are introduced by Box and Khan [11, 12]. For multi mode vibration reduction of offshore wind turbine under seismic excitation, Hussan [13] introduces a multiple tuned mass damper (MTMD) technique.

The use of particle damping in wind turbine blade is not much explored in as found through the relevant literature. Therefore, in this research the focus is on the same.

\section{Particle damping method}

The use of a particle damping method is based on the ability of contact interactions using a small number of parameters that capture the most important contact properties. Forces between cavity walls and individual particles are calculated based on force-displacement relations.

Forces created due to particle-cavity and particle-particle impacts are the main aspect for modeling. Spherical particles, A and B with radii $r_{A}$ and $r_{B}$ with particle centres separated by distance $D$ is shown in Fig. 1(a). At approach e is positive, at that time two particles interact with each other. The approach can be defined as: 
$e=\left(r_{A}+r_{B}\right)-D$

contact forces between two colliding balls become:

$\vec{f}=f^{n} \vec{N}^{n}+f^{s} \vec{N}^{s}$,

where, $f^{n}$ - normal force, $f^{s}$ - shear force, $\vec{N}^{n}$ - unit vector in normal direction and $\vec{N}^{s}$ - unit vector in shear direction. $C_{N}, C_{S}, K_{N}, K_{S}$ damp constants and stiffness respectively.

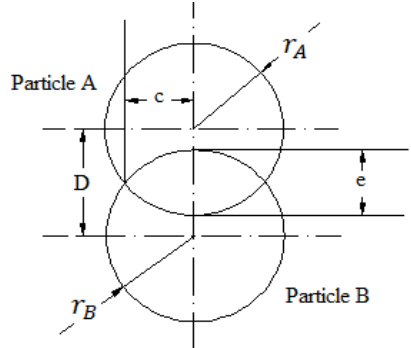

a)

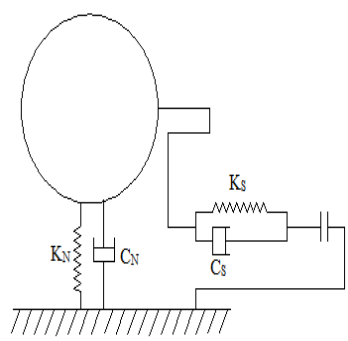

b)

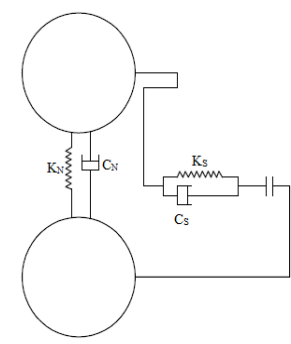

c)

Fig. 1. a) Particle-particle impact parameters, b) ball-wall spring mass diagram,

c) ball-ball spring mass diagram

\section{The experimental setup}

Fig. 2 shows a block diagram of the experimental set-up. Three blades having $1525 \mathrm{~mm}$ length each are mounted on flange connected to a shaft. The shaft is supported with a bearing, considering that all vibrations of the blade are transmitted through the flange and shaft to the bearing. Three-directional accelerometer is mounted on the bearing and it transmits signals to FFT analyzer (Bruel and Kjaer) and further from the analyzer to the display unit. Fig. 3 shows $9 \mathrm{~mm}$ spherical ball, particle damper container. Fig. 4 shows the experimental set-up of $1 \mathrm{~kW}$ wind turbine (a) FEA Model (b) test set-up. In all tests, considering the size of spherical particles as $9 \mathrm{~mm}$ having material containing chemical compositions of $0.010 \% \mathrm{Mo}, 0.050 \% \mathrm{Ni}, 0.98 \% \mathrm{C}, 0.33 \%$ $\mathrm{Mn}, 0.25 \% \mathrm{Si}, 0.010 \% \mathrm{~S}, 0.012 \% \mathrm{P}, 1.40 \% \mathrm{Cr}$. Container diameter is $48 \mathrm{~mm}$, and height is $28 \mathrm{~mm}$ having material of Poly-propylene (PP).

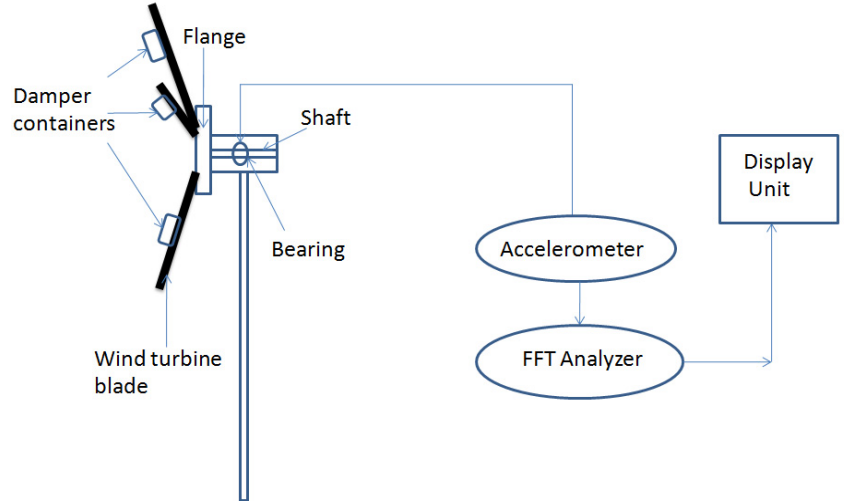

Fig. 2. Block diagram of the experiment set-up

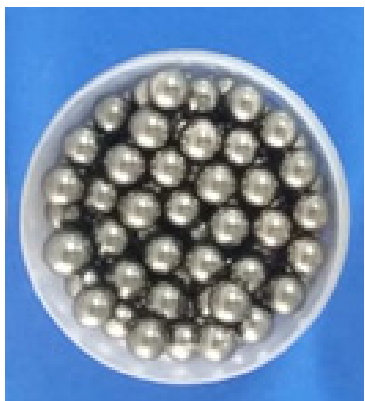

Fig. 3. Container with particle damper

\subsection{Parameters for testing}

Position of Damper: Fig. 5(a) to (d) show a particle damper mounted on four positions on each blade at the difference of $300 \mathrm{~mm}$ from the tip of the blade as $300 \mathrm{~mm}, 600 \mathrm{~mm}, 900 \mathrm{~mm}$ and 
$1200 \mathrm{~mm}$ respectively. At each position, a container is mounted externally on all the three blades at the same time.

RPM of Blade: In this research, three different rpm i.e. $60 \mathrm{rpm}, 70 \mathrm{rpm}$ and $80 \mathrm{rpm}$ are kept. Therefore, the first takes the readings on without damping conditions and compares results with with-damping conditions.

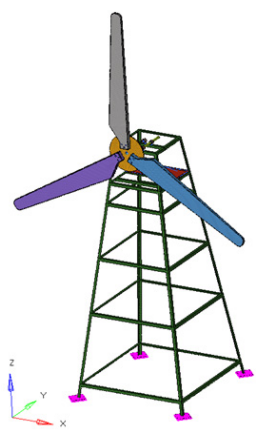

a)

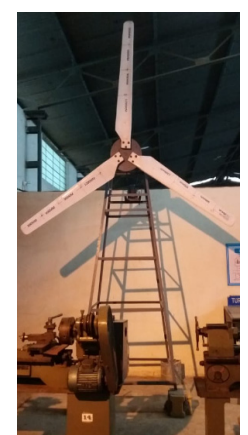

b)

Fig. 4. Experimental set-up of $1 \mathrm{~kW}$ wind turbine a) FEA model and b) actual experimental set-up

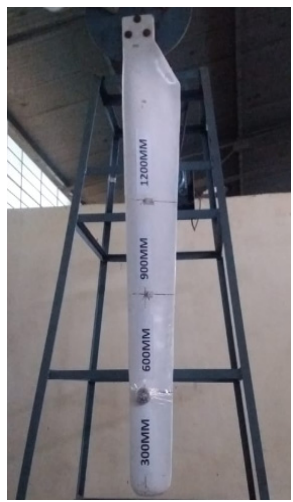

a)

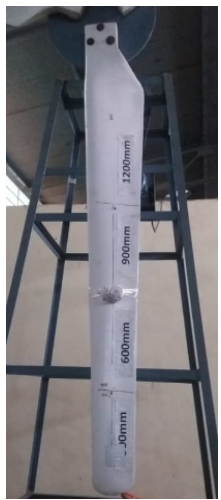

b)

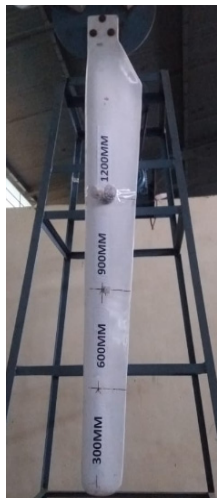

c)

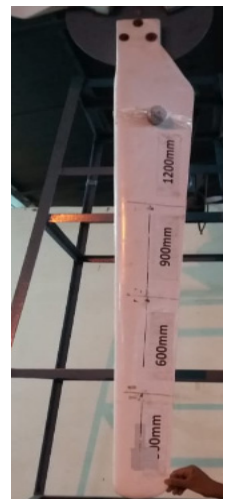

d)

Fig. 5. a) Damper at $300 \mathrm{~mm}$, b) damper at $600 \mathrm{~mm}$, c) damper at $900 \mathrm{~mm}$, d) damper at $1200 \mathrm{~mm}$

\section{Results and discussion}

FEA model of the test set-up is prepared using hypermesh software by taking 2D mixed mesh and $3 \mathrm{D}$ tetra mesh elements having 161073 nodes, 65761 elements. First, a test was conducted without damping using FEA results were compared with another similar test conducted through experimental set up. For without damping conditions taking reading at $90 \mathrm{rpm}$ randomly gives result as $1.57 \mathrm{~m} / \mathrm{s}^{2}$ at $50.96 \mathrm{~Hz}$ from CAE and acceleration of $1.66 \mathrm{~m} / \mathrm{s}^{2}$ at $46.87 \mathrm{~Hz}$ from test set-up, which is close to $90 \%$ CAE results. Table 1 shows all the testing results with the first two modes for different rpm and position. Fig 6. shows the acceleration versus frequency with frequency range up-to $1000 \mathrm{~Hz}$. Fig. 5(a) to (d) show damper at $300 \mathrm{~mm}, 600 \mathrm{~mm}, 900 \mathrm{~mm}$ and $1200 \mathrm{~mm}$ respectively. Fig. 6 shows testing results of damping with different positions and at different rpms. In all the results, the five peak modes are shown, and their magnitudes are also shown. Fig. 7 shows all results of undamped and damped conditions together for the first two modes. 


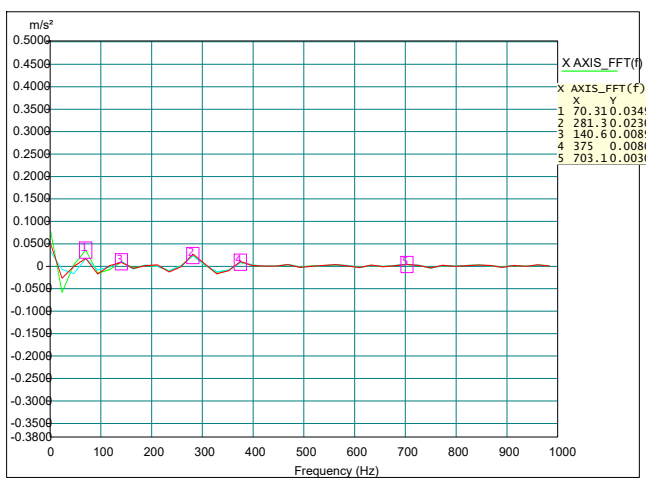

a) $60 \mathrm{rpm}, 1200 \mathrm{~mm}$ position

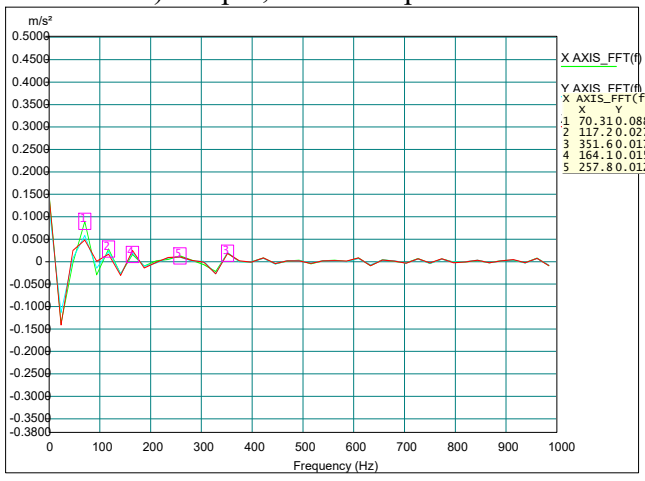

c) $80 \mathrm{rpm}, 1200 \mathrm{~mm}$ position

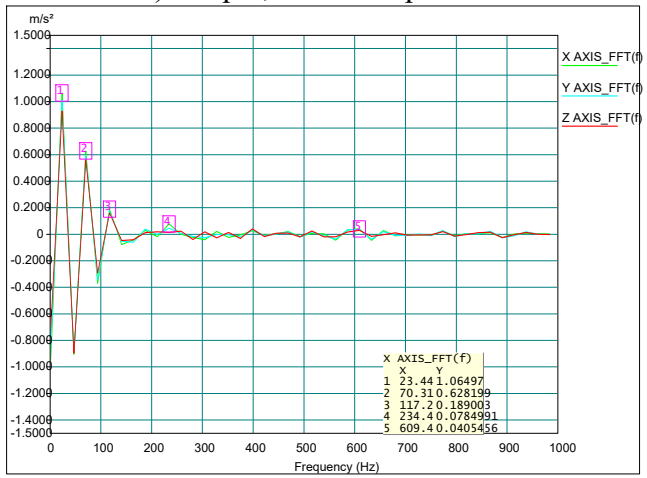

e) $70 \mathrm{rpm}, 900 \mathrm{~mm}$ position

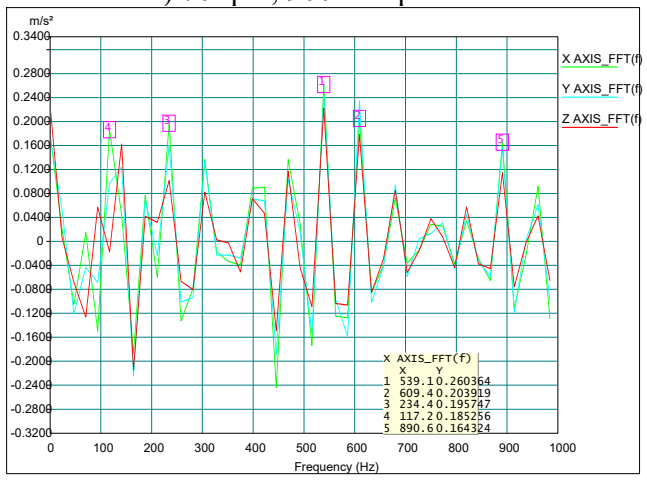

g) $60 \mathrm{rpm}, 600 \mathrm{~mm}$ position

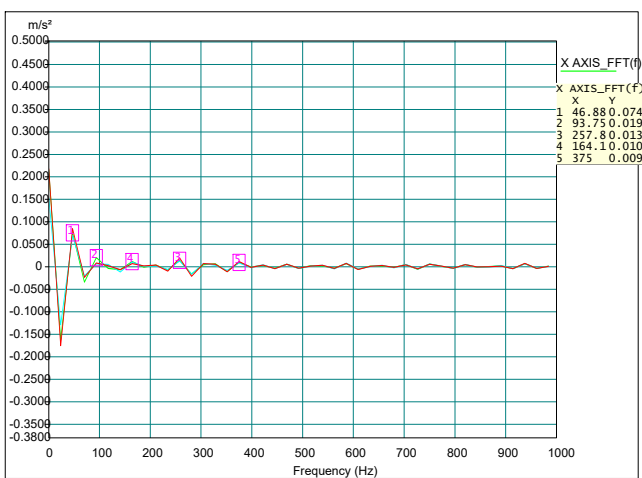

b) $70 \mathrm{rpm}, 1200 \mathrm{~mm}$ position

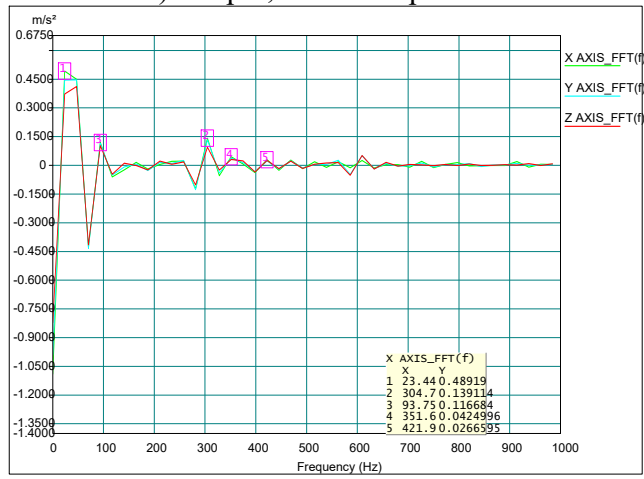

d) $60 \mathrm{rpm}, 900 \mathrm{~mm}$ position

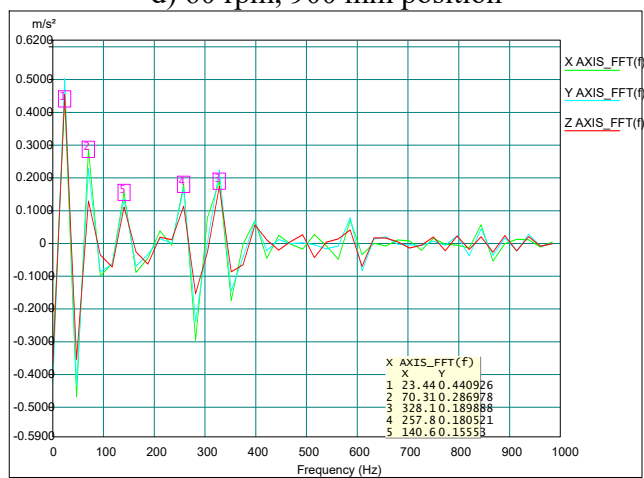

f) $80 \mathrm{rpm}, 900 \mathrm{~mm}$ position

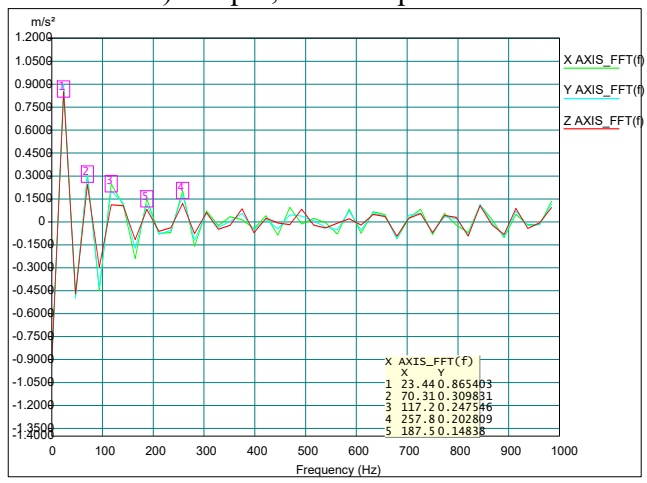

h) $70 \mathrm{rpm}, 600 \mathrm{~mm}$ position

Fig. 6. Testing results of damping with different positions at different rpm 


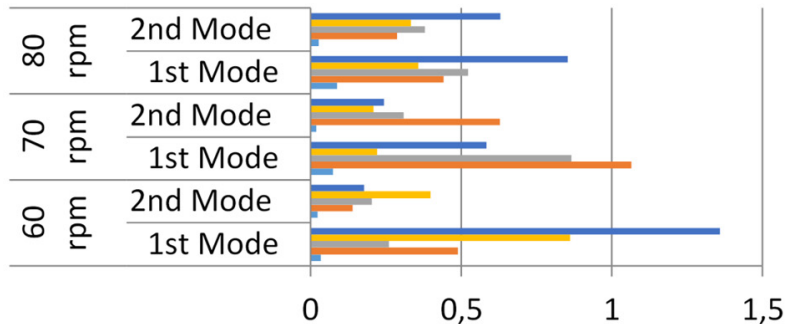

Fig. 7. Combined results of undamped and damped cases

Table 1. Testing results of acceleration $\left(\mathrm{m} / \mathrm{s}^{2}\right)$ for different $\mathrm{rpm}$ and position

\begin{tabular}{|c|c|c|c|c|c|c|}
\hline \multirow{2}{*}{ Position of damper } & \multicolumn{2}{|c|}{$60 \mathrm{rpm}$} & \multicolumn{2}{|c|}{$70 \mathrm{rpm}$} & \multicolumn{2}{c|}{$80 \mathrm{rpm}$} \\
\cline { 2 - 7 } & $\begin{array}{c}1 \mathrm{st} \\
\text { Mode }\end{array}$ & $\begin{array}{c}\text { 2nd } \\
\text { Mode }\end{array}$ & $\begin{array}{c}1 \mathrm{st} \\
\text { Mode }\end{array}$ & $\begin{array}{c}\text { 2nd } \\
\text { Mode }\end{array}$ & \multicolumn{1}{c|}{$\begin{array}{c}\text { 1st } \\
\text { Mode }\end{array}$} & $\begin{array}{c}2 \mathrm{nd} \\
\text { Mode }\end{array}$ \\
\hline $\begin{array}{c}1200 \mathrm{~mm} \text { position } \\
\text { (Damped) }\end{array}$ & 0.034 & 0.023 & 0.074 & 0.019 & 0.088 & 0.027 \\
\hline $900 \mathrm{~mm}$ position (Damped) & 0.489 & 0.139 & 1.064 & 0.628 & 0.4409 & 0.2869 \\
\hline $600 \mathrm{~mm}$ position (Damped) & 0.26 & 0.203 & 0.865 & 0.309 & 0.522 & 0.379 \\
\hline $300 \mathrm{~mm}$ position (Damped) & 0.862 & 0.398 & 0.221 & 0.208 & 0.357 & 0.333 \\
\hline Undamped & 1.359 & 0.177 & 0.583 & 0.243 & 0.853 & 0.629 \\
\hline
\end{tabular}

\section{Conclusions}

Comparing dampers for all the four positions, optimum results are received at $1200 \mathrm{~mm}$ position location of damper, because at each 60,70 and $80 \mathrm{rpm}$ difference of acceleration value between with and without damping is greater. Comparing three different rpms, if results are compared, at $60 \mathrm{rpm}$ rotation and $1200 \mathrm{~mm}$ position damper location gives good results.

\section{References}

[1] Thomsen K., Petersen J. T., Nim E., Øye S., Petersen B. A method for determination of damping for edgewise blade vibrations. Wind Energy, Vol. 3, Issue 4, 2000, p. 233-246.

[2] Qiu Dapeng, Chen Jianyun Dynamic responses and damage forms analysis of underground large scale frame structures under oblique SV seismic waves. Soil Dynamics and Earthquake Engineering, Vol. 117, 2019, p. 216-220.

[3] Giguère P., Selig M. S., Tangler J. L. Blade design trade-offs using low-lift airfoil for stall-regulated HAWTs. Journal of Solar Energy Engineering, Vol. 121, 1999, p. 217-223.

[4] Saranyasoontorn K., Manuel L. Efficient models for wind turbine extreme loads using inverse reliability. Journal of Wind Engineering and Industrial Aerodynamics, Vol. 92, 2005, p. 789-804.

[5] Ishizaki H. Wind profiles, turbulence intensities and gust factors for design in typhoon-prone regions. Journal of Wind Engineering and Industrial Aerodynamics, Vol. 13, 1983, p. 55-66.

[6] Maalawi K. Y., Badawy M. T. S. A direct method for evaluating performance of horizontal axis wind turbines. Renewable and Sustainable Energy Reviews, Vol. 5, 2001, p. 175-190.

[7] Duquette M. M., Visser K. D. Numerical implications of solidity and blade number on rotor performance of horizontal-axis wind turbines. Journal of Solar Energy Engineering, Vol. 125, Issue 4, 2003, p. 425-432.

[8] Murtagh P. J., Ghosh A., Basu B., Broderick B. M. Passive control of wind turbine vibrations including blade/tower interaction and rotationally sampled turbulence. Wind Energy, Vol. 11, Issue 4, 2008, p. 305-317.

[9] Krenk S., Svendsen M. N., Hogsberg J. Resonant vibration control of three-bladed wind turbine rotors. AIAA Journal, Vol. 50, Issue 1, 2012, p. 148-161.

[10] Fitzgerald B., Basu B., Nielsen S. R. K. Active tuned mass dampers for control of in-plane vibrations of wind turbine blades. Structural Control and Health Monitoring, Vol. 20, Issue 12, 2013, p. $1377-1396$. 
[11] Box G. E. P., Draper N. R. Response Surfaces, Mixtures, and Ridge Analyses. 2nd ed., John Wiley and Sons, New Jersey, USA, 2007.

[12] Khan A., Do J., Kim D. Cost effective optimal mix proportioning of high strength self-compacting concrete using response surface methodology. Computers and Concrete, Vol. 17, Issue 5, 2016, p. $629-648$.

[13] Mosaruf Hussan, Mohammad Sabbir Rahman, Faria Sharmin, Dookie Kim Multiple tuned mass damper for multi-mode vibration reduction of offshore wind turbine under seismic excitation. Ocean Engineering, Vol. 160, 2018, p. 449-460. 